\title{
Connecting health systems research ethics to a broader health equity agenda
}

Bridget Pratt

Only one thing matters. Universal Health Coverage. Nothing else. Our path up the mountain to UHC will be steep. But we must not shirk our duty to get the world there.

-Richard Horton, speaking at the $2^{\text {nd }}$ Global Symposium on Health Systems Research in 2012

Global funding for [health systems research]...is less likely to address deeper, more structural questions...or to support action research that actively engages stakeholders in improving health systems. In part, this is due to the nature of new funding agencies in the field who are frequently focused on achieving global targets... It is unclear to what extent local actors in LMIC health systems would frame their research concerns in the same way as global stakeholders.

-Sara Bennett, Irene Akua Agyepong, Kabir Sheikh, Kara Hanson Freddie Ssengooba, \& Lucy Gilson (2011)

Hyder et al.'s (2013) article demonstrates that the distinctive features of health systems research give rise to nuanced ethical considerations in areas like informed consent, risk, and benefit. Yet it focuses primarily on ethical issues that fall within the purview of institutional review boards (IRBs). This gives an impression (likely not intended by the authors) that the scope of health systems research ethics principally covers the traditional range of issues that arise at the project level in international research. In doing so, the article largely fails to highlight how the ethics of health systems research in low and middle-income countries (LMICs) is fundamentally connected to a "broader bioethics agenda of equity and population health" (Daniels 2006).

Health systems research in LMICs has been specifically identified as a crucial component of a health research enterprise dedicated to advancing health equity between and within nations (WHO Task Force on HSR 2005; WHO Task Force on Research Priorities for Equity in Health and WHO Equity Team 2005). Such research can assess where health systems' performance falls short on equity dimensions, determine why those shortcomings occur, develop and evaluate strategies to 
address them, and/or actively engage communities in any or all three of these processes. An overarching question for health systems research ethics should, therefore, be: to what extent is health systems research in LMICs actually structured to effectively reduce health disparities between rich and poor countries? And to improve the health of the vulnerable and marginalised within LMICs?

Accounts of global justice in health from political philosophy suggest that international research should improve the health of worst-off populations through not only the conduct of collaborative studies but also efforts to build host country research capacity (Pratt, Zion, and Loff 2012). This position has also been espoused by bioethicists Solomon Benatar and Peter A. Singer (2010). Achieving health justice isn't simply about assisting LMICs by carrying out needed research to strengthen their health systems. It is also about building their health research systems' capacity to meet their populations' needs. The aim is for LMICs to become capable (of performing research) in their own right rather than to be perpetual recipients of rich countries' help.

Recent research suggests that a number of ethical issues exist that relate to the ability of health systems research in LMICs to promote improved health for the worstoff and research capacity in host countries (Pratt and Loff 2012; Pratt and Hyder in press). These issues were identified through analysis of the literature on health systems research in LMICs. First, the interaction between priority setting at the national and global levels in health systems research is potentially troubling. Priority setting can be conceptualised as consisting of two main processes-identification of priorities and implementation of priorities. The former entails stakeholders' 
determination of a set of either global or national health systems research priorities. The latter consists (in part) of the selection of research projects to finance by funders. Unlike clinical research, health systems research is necessarily contextdriven because health systems vary considerably between countries and are quite complex (Bennett et al. 2011). Countries' health systems research priorities should, therefore, be strongly informed by an understanding of the national and sub-national health systems that they are intended to improve.

Yet health systems research has increasingly been linked to the achievement of a number of global health and development priorities such as the Millennium Development Goals (MDGs), universal health coverage, and, most recently, peoplecentred health systems (WHO Task Force on HSR 2005; Beijing Statement 2012). As indicated by Lancet editor Richard Horton's instruction to the health systems research community at the $2^{\text {nd }}$ Global Symposium for Health Systems Research in 2012 (included at the start of this editorial) (Quick 2012), the post-2015 health development agenda will focus on universal health coverage and health systems research in LMICs should align with that agenda. This emphasis on achieving global targets may result in national processes' failure to identify research priorities that reflect countries' specific health system performance weaknesses on dimensions of equity. An ethical issue in health systems research is, therefore, that global priorities influence and possibly determine national priorities for such research in LMICs (Pratt and Hyder in press).

The dominance of global priorities is reinforced at the implementation stage of the priority setting process, where current funding mechanisms likely crowd out health 
systems research that is responsive to local needs in favour of health systems research on service delivery and scale up of interventions geared to support the achievement of global targets like the MDGs (Bennett et al. 2011; Sheikh et al. 2011). Gonzalez-Block (2004) showed that, of the health systems research being performed in LMICs, international donors' priorities align most consistently with the research topics being pursued. As a result, there was a low emphasis of research on human resources, equity, and health information systems relative to service delivery.

Funding for health systems research in LMICs primarily comes from international sources. Bilateral aid agencies are major funders of such research (Bennett et al. 2008). As a result, like the MDGs before it, the post-2015 development agenda will also have a huge impact on what health systems research gets funded in LMICs.

The relationship between national and global priorities in health systems research is an area of ethical inquiry that needs to be explored (Pratt and Hyder in press). It raises questions such as: what does a fair priority setting process for health systems research look like at the global level and the national level? How should national and global research agendas and priorities for health systems research align? What features do health systems research priorities that advance health equity have? Do global or national priorities meet such criteria? Is it ethically acceptable for funders to align their funding practices with global priorities or must national priorities be given primary consideration?

Further reinforcing the tendency for global priorities to dominate health systems research in LMICs is the lack of demand and capacity for national priority setting in 
some countries. This, in turn, highlights an ethical concern relating to the nature of research capacity strengthening for health systems research. Such efforts, in accordance with funding opportunities, tend to focus on the individual and institutional levels rather than building the capacities of national health research systems in LMICs to carry out core functions like priority setting (Pratt and Hyder in press).

Ethical investigation into the nature of health systems research capacity strengthening is needed. Questions to explore might include: how should resources be fairly allocated amongst capacity building at the individual, institutional, and systems levels? Beyond research capacity strengthening at the project level, what are the capacity building obligations of health systems research consortia? Are funders, particularly development agencies, obligated to fund consortia dedicated solely to research capacity building such as the Consortium for Health Policy \& Systems Analysis in Africa (CHEPSAA)? Is it ethical for funders like the UK Department for International Development to decide to limit their support for health systems research capacity building to the individual and institutional levels? If so, who is obligated to fund capacity building at the systems level in LMICs?

Finally, a third area of ethical concern relating to health systems research's capacity to advance health equity is the unequal allocation of health research resources between biomedical and non-biomedical research. Of the limited funding available for international research, most is channelled towards the development of new interventions. In 2005, US\$ 2.6 billion was spent on international research in LMICs by foreign public, philanthropic and private for-profit funders, but estimates show that 
only US\$134 million is spent annually on health systems research in LMICs (AHPSR 2004; GFHR 2005). Similarly, money for research capacity strengthening in LMICs is mainly allocated to clinical and epidemiological research (Bennett et al. 2008).

The imbalance is largely determined by the laws and policies governing research in high-income countries. These laws and policies create incentives to conduct forms of research that can lead to commercializeable outputs like basic science and clinical research. The regulatory environment in high-income countries privileges the economic function of their national health research systems over their healthpromoting function (Pratt and Loff 2012). This raises ethical questions regarding the structure of R\&D systems: to what extent is it ethical for such systems to favour national economic competitiveness above health and equity in their design? Do governments and funders have ethical obligations to ensure a more balanced allocation of funding to biomedical versus non-biomedical research? If so, what is the content of their obligations?

Ultimately, health systems research ethics' scope should include areas like priority setting, resource allocation, and capacity building. If we accept that health systems research has high potential to help reduce health disparities between and within countries, then it is important for bioethics to investigate the aforementioned issues and develop guidance on addressing them in order to ensure that health systems research in LMICs contributes most effectively to that aim. 


\section{References}

Alliance for Health Policy and Systems (AHPSR). 2004. Strengthening Health Systems in Developing Countries: The Promise of Research on Policy and Systems. Geneva: Alliance for Health Policy and Systems Research.

Beijing Statement from the Second Global Symposium on Health Systems Research. 2012. Available from: http://www.who.int/alliancehpsr/alliancehpsr_beijingstatement.pdf.

Benatar, S.R., and P.A. Singer. 2010. Responsibilities in international research: A new look revisited. Journal of Medical Ethics 36: 194-197.

Bennett, S., T. Adam, C. Zarowsky, V. Tangcharoensathien, K. Ranson, T. Evans, and A. Mills. 2008. From Mexico to Mali: Progress in health policy and systems research. Lancet 372: 1571-1578.

Bennett, S., I.A. Agyepong, K. Sheikh, K. Hanson, F. Ssengooba, and L. Gilson. 2011. Building the field of health policy and systems research: An agenda for action. PLoS Medicine 8: e1001081.

Daniels, N. 2006. Equity and population health: Towards a broader bioethics agenda. Hastings Center Report 36: 22-35

Global Forum for Health Research (GHFR). 2008. Monitoring financial flows for health research 2008. Geneva: GFHR. 
Gonzalez-Block, M.A. 2004. Health policy and systems research agendas in developing countries. Health Research Policy and Systems 2: 6.

Hyder, A.A., A. Rattani, C. Krubiner, A.M. Bachani, and N.T. Tran. 2013. Ethical review of health systems research in low and middle income countries: A conceptual exploration. American Journal of Bioethics, in press.

Pratt, B., and B. Loff. 2012. Health research systems: Promoting health equity or economic competitiveness? Bulletin of the World Health Organization 90(1): $55-62$.

Pratt, B., D. Zion, and B. Loff. 2012. Evaluating the capacity of theories of justice to serve as a justice framework for international clinical research. American Journal of Bioethics 12: 30-41.

Pratt B., and A.A. Hyder. Applying a global justice lens to health systems research ethics: An initial exploration. Kennedy Institute of Ethics Journal, in press.

Quick, J.D. (2012). 10 Takeaways from Beijing: Second Global Symposium on Health Systems Research. Available at: http://msh.dldev.com/blog/2012/12/05/10-takeaways-from-beijing-second-globalsymposium-on-health-systems-research. 
Sheikh, K., L. Gilson, I.A. Agyepong, K. Hanson, F. Ssengooba, and S. Bennett. 2011. Building the field of health policy and systems research: Framing the questions. PLoS Medicine 8: e1001073.

WHO Task Force on Health Systems Research. 2005. The Millennium Development Goals will not be Attained Without New Research Addressing Health System Constraints to Delivering Effective Interventions. Geneva: WHO.

WHO Task Force on Research Priorities for Equity in Health, and the WHO Equity Team. 2005. Priorities for research to take forward the health equity policy agenda. Bulletin of the World Health Organization 83: 948-53. 


\section{University Library}

\section{- M M N E R VA A gateway to Melbourne's research publications}

Minerva Access is the Institutional Repository of The University of Melbourne

Author/s:

Pratt, B

Title:

Connecting Health Systems Research Ethics to a Broader Health Equity Agenda

Date:

2014-02-01

Citation:

Pratt, B. (2014). Connecting Health Systems Research Ethics to a Broader Health Equity Agenda. AMERICAN JOURNAL OF BIOETHICS, 14 (2), pp.1-3. https:// doi.org/10.1080/15265161.2014.881213.

Persistent Link:

http://hdl.handle.net/11343/56562 